$813 / 19$ MASTER

ESCADT: A FORTRAN Code for Computing the Positions and Areas of X-Ray Photoelectron Spectral Peaks 
LA-7910

UC.4

Issued: September 197

\title{
ESCADT: A FORTRAN Code for Computing the Positions and Areas of X-Ray Photoelectron Spectral Peaks
}

\author{
Lawrence E. Cox
}




\title{
ESCADT: A FORTRAN CODE FOR COMPUTING THE POSI'TIONS ANO AREAS OF X-RAY PHOTOELECTRON SPECTRAL PEAKS
}

\author{
by
}

\author{
Lawrence E. Cox
}

\begin{abstract}
Program ESCADT uses least-squares-derived convoluting numbers to smooth and differentiate $x$-ray photoelectron spectra. Peak maxima are located by finding zero crossings of the first derivative and refined using a cubic polynomial fitting procedure. Background points are located using the product of the absolute value of the first derivative and the smoothed ordinate value. Peak areas, using both linear and scattered electron backgrounds, are computed. Spectra are corrected for changes in instrument sensitivity and energy calibration with gold-standard data retrieved from a disk file. Five determinations of the gold $4 f$ peak positions yielded standard deviations of 0.011 and $0.031 \mathrm{eV}$ for the $4 f_{7 / 2}$ and $4 f_{s / 2}$ peaks, respectively. The relative standard deviation for the computed areas was $0.85 \%$.
\end{abstract}

\section{INTRODUCTION}

Since its inception more than a decade ago, electron spectroscopy for chemical analysis (ESCA) has provided numerous insights into the nature of chemical bonding. Its ability to measure small shifts in core-level binding energies ccupled with its extreme surface sensitivity make ESCA a uniquely powerful tool for the qualitative and quantitative characterization of the outermost, 5-20 atomic layers of almost any solid (or gaseous) material.

Although the great promise of ESCA for the elucidation of molecular charge distribution and for quantitative analyses was recognized by Siegbahn et al. ${ }^{1}$ early in the development of the technique, subsequent investigators have encountered a variety of difficulties that seem to leave open to question the technique's reliability as a routine analytical tool. Among the earliest studies of the analytical applicability of ESCA was the measurement of peak intensities (height and area) of a variety of elements in compounds containing sodium, potassium, or fluorine. ${ }^{2}$ By comparing the intensities of other element lines to those of the reference element, a set of sensitivity factors of standard intensities was ob. tained. It was found, however, that such intensity ratios (for example, $\mathrm{Na}: \mathrm{F}$ ) varied considerably from compound to compound, presumably because of extrinsic or intrinsic electron energy-loss processes that are characteristic of a particular chemical environment. Although some progress for understanding these processes is being made, the theory is not yet sufficiently well developed as to have much predictive value. The accuracy attainable in quantitative analyses by ESCA may well be limited ultimately by intensity variations of this nature.

A more immediate problem in the development of ESCA as an analytical technique arises from the present lack of generally accepted procedures for sample preparation, instrument calibration, and data handling. That binding energy measurements from different laboratories often show disconcerting 
discrepancies has been recognized for some time. Perhaps more disturbing is the lact that interlaboratory measurements on the same material often disagree by considerably more than the error quoted by either laboratory. The severity of the calibration problem was graphically illustrated by a recent round-robin experiment in which the participants' measurements of the binding energy difference between the $\mathrm{Au} 4 \mathrm{f}_{7 / 2}$ and $\mathrm{Cu} 2 \mathrm{p}_{3.2}$ lines differed by up to $2 \mathrm{eV}{ }^{3}$ Several lechniques for referencing such measurements have been proposed (adventitious carbon layer, gold decoration. and graphite admixture), but none of them is without shortcomings.

Quantitative analysis using peak areas is plagued by equally insidious problems, primarily because of uncertainties about the nature of the background resulting from inelastically scattered electrons. The spectra of metallic samples are often particularly intractable because small energy losses resulting from valence and conduction band electrons give rise to a base-line shift beneath the peak of interest, and larger energy-loss processes, such as plasmon peaks, produce rather ill-defined structures at lower kinetic energy. Owing to an insufficiently delailed understanding of these processes, the analyst has usually resorted to rather subjective criteria when selecting representative background points. Also, techniques of widely varying sophistication-from planimetry to computer curve fitting-are used for the measurement of peak areas. That alarming variability among reported quantitative measurements exists is not, therefore, unexpected.

Full realization of ESCA's analytical potential must await the formulation of more comprehensive theoretical treatments of photoionization and electron-loss processes in solids. At present, however, the most pressing need is for precisely defined criteria that will allow ESCA users to obtain peak positions and areas in a logical and reproducible manner. Program ESCADT represents some progress toward this end.

\section{DESCRIPTION OF THE CODE}

\section{A. General Information}

Program ESCADT was written to be used in conjunction with the Physical Electronics Industries (PHI) Multiple-Technique Analytical Computer
System (MACS). In its present form, the code processes ESCA data for a single spectral region. In the multiplex mode, MACS allows the acquisition of data for several regions, and if sufficient computer memory is available, ESCADT could be modified easily to process such data. We are currently using a Digital Equipment Corporation (DEC) 11/04 computer with $28 \mathrm{k}$ words of memory and a Plessey PMIJ)/11B 5-megabyte disk. The computer operating system is DEC's RT-11, version 3. A complete program listing can be found in Appendix A. To facilitate modifying the code for use on other computers, a description of the input parameters is given in Appendix B.

\section{B. Initial Dialogue}

Data files created by MACS software are binary and therefore have an RT-11 extension of "OBJ." The response to the initial query "DEVICE AND FILE NAME?" will be "DEV:FILENM.OBJ" where DEV is an RT-11 device name, FILENM is the name previously assigned to the data file, and $O B J$ indicates a binary file. The computer then reads the specified file consisting of an Acquisition Control Block ( $\mathrm{ACB}$ ) and a digitized spectrum.

The following acquisition parameters are printed: creation date of the file, the number of scans of the designated region (NO. SCANS), the data acquisition time at each point for each scan (T/S, in ms), $\mathbf{x}$ ray source emission current and operating voltage (X-RAY MA and X-RAY KV), analyzer pass energy (PASS ENERGY, in eV), upper binding energy limit of the scan (BINDING ENERGY U.L.), scan range (RANGE EV), scan step size (EV/STEP), number of disk blocks occupied by the file (\# DISC BLOCKS), number of data points in the spectrum (\# DATA POINTS), and sample identification (SAMPLE ID). See Appendix C for a typical run.

ESCADT provides for both binding energy and intensity calibration of spectra. Calibration information is written into a disk file when a goldcalibration spectrum is processed. If the binding energy of the $A u 4 f_{7 / 2}$ peak differs from the accepted value of $83.8 \mathrm{eV}$, subsequently processed spectra are corrected accordingly. The magnitude of the correction, as well as the date of the calibration run, are printed. Also, at the operators option, the normalized area of the Au 4 f peaks may be iecorded for later reference. This is usually done immediately 
after sputtering the gold-calibration standard and allows correction for any long-term changes in instrument sensitivity. The operator enters "Al! CAL2" in the ACB comment field if both binding energy and intensity information is to be recorded on the disk and "AU CAL1" if only binding energy" calibration is desired.

The program next requests input of the neutralizer emission current. The value entered is for reference purposes only; it is not used computationally. The spectrometer work function is required for calculating photoelectron kinetic energy: "WORK FUNCTION (EV)" is printed as a prompt, preceding operator input.

\section{Location of Peaks}

For the location of peak maxima and suitable background points, ESCADT uses polynomial smoothing and differentiation with least-squaresderived convoluting numbers. The theory and application of this method was described by Sterrett and later by Savitzky and Golays. Briefly, the method obtains smoothed values for the ordinate and the first derivative for any set of $x$ and $y$ values that can be represented reasonably well by a polynomial ( $2^{\text {na }}$ degree in this case) over short intervals and in which the $x$ values are equally spaced. We have found that an 11-point quadratic gives good results for spectra digitized at $0.1-\mathrm{eV}$ intervals; however, point spreads of 9 to 21 points can be selected. Particularly noisy spectra may warrant the use of a smoothing interval larger than 11 points; whereas a 9-point spread might be appropriate for digitization intervals larger than $0.1 \mathrm{eV}$. The smoothing coefficients are stored as an ASCII file on the disk (RK1:SMCOEF.DAT). The values are given in Appendix D.

After generating the smoothed values and first derivatives [SMOTH $(1, \mathrm{~N})$ and $\operatorname{SMOTH}(2, \mathrm{~N})$, respectively\}, peak maxima are located by examining the latter for zero crossings. That a zero crossing is not a result of noise is established by requiring that the average value of the first derivative exceed a specified threshold for a designated distance on either side of the suspected peak maximum. At the completion of the search, the number of peaks found is compared to the number requested, and the threshold is adjusted iteratively until the specified number of peaks is found. The peaks located will generally be the most prominent ones in the spectrum. Therefore, to identify smaller spectral features, the number of peaks specified must include all peaks more prominent than those of interest.

\section{Peak Widths and Background Points}

The most convenient measure of peak width is the full width at half maximum height (FWHM). Accurate estimation of this quantity requires hase-line subtraction; however, the separation of the points of maximum and riinimum slope on the peak sicles provides a reasonably accurate first approximation. These points are located starting at the peak maximum and proceeding down either side. The average of three points is used to furt her reduce the effects of noise.

The search for background points is begun at a distance equal to twice the peak width on each side of the maximum. Although the criteria for suitable background points are somewhat arbitrary, we have chosen them to correspond as closely as possible to what more traditional methods have used. that is. relatively flat areas and/or minima near the peak. We have found that spectral points at which the product of the smoothed $y$ value and the absolute value of the first derivative is a ninimum are generally suitable for delimiting peak areas. The factor 0.5 is added to the derivative so that it will not dominate the product at slopes near zero.

\section{E. Refining Peak Positions}

Steinhaus et al. ${ }^{6}$ have shown that accurate peak positions can be obtained by computing the max. inum in a least-squares polynomial that is fitted through an appropriate number of points near the estimated peak maximum. This approach has proved reliable for ESCA spectra and is used in ESCADT. A cubic polynomial is fitted through a number of points (NPOLY) equal to half the peak width plus one. NPOLY is restricted, however, such that $7 \leqq N P O L Y \leqq 15$. The refined peak position is found by differentiating the cubic polynomial, setting the result equal to zero, and solving the resulting quadratic equation. For a cubic polynomial of the form $a x^{3}+b x^{2}+c x+d$, the desired solution is

$$
x_{\max }=\frac{-2 b-\sqrt{4 b^{2}-12 a c}}{6 a} \text {. }
$$


In rare cases, the cubic coefficient is zero within computer accuracy and Eq. (1) cannot be solved. If this sccurs, the program substitutes a quadratic equation for the cubic polynomial. Also, if the average error in the polynomial fit exceeds $5 \%$, a warning diagnostic is printed.

\section{F. Peak Overlap}

ESCA spectral peaks frequently consist of two or more partially resolved peaks. Often, it is the area of the composite peak that is of interest because areas computed using a background point between the peaks would give misleading results. The criterion used for peak overlap is that the separation between adjacent peaks is less than 1.5 times the sum of the individual peak widths. If the operator chooses to omit the background point between the peaks, the partially resolved multiplet is then considered as a single peak for integration. However, the positions of both maxima are still printed. The check for overlap starts with the peak at highest binding energy and is continued until all peaks have been considered. Also, a diagnostic is printed if a peak is less than four times the peak width from either end of the spectrum. If, after inspecting a peak, the operator decides that the area cannot be accurately determined, that peak may be omitted from consideration.

\section{G. Base-Line Slope Correction}

Spectra obtained with spectrometers possessing a transmission function that is inversely proportional to kinetic energy often show pronounced base-line slopes at low kinetic energies. Because the first derivative is used for establishing background points, such slopes can adversely affect the reliability of peak-area calculations. ESCADT can subtract a linear base line and recalculate the pertinent spectral parameters. The slope of the base line to be subtracted is obtained by averaging the value of the first derivative at all points except those bounded by the background points for each peak. The linear function defined by this slope and the lowest $y$ value in the spectrum are then subtracted from the spectrum. The corrected spectrum is subjected to the entire smoothing and peak-locating routine.

\section{H. Peak Areas}

Two methods are used for computing peak areas. The first involves adding all ordinate values above the line connecting the previously determined background points and multiplying the sum by the binding energy step width. The second method is based on the fact that inelastically scattered photoelectrons are detected at lower kinetic energies than those that are elastically scattered. Therefore, the background amplitude at any point beneath the peak is proportional to the total peak area at higher kinetic energy. ESCADT designates areas computed in this way. "SB" is for an electron scattered background, and "LB" indicates a linear background. The ratio of each peak area to that of the Au 4 f peak area (see above) is also printed; these values are designated "PEAK AREA/AU."

\section{Analyzer Transmission Function and Escape Bepth Correction}

As discussed above, the cylindrical mirror analyzer with preretarding electron optics exhibits a transmission function that is inversely proportional to kinetic energy. To compare measured peak-area ratios with theoretical photoionization cross sections, a correction must be applied to the raw data. In addition, the variation in electron inelastic mean free path (IMFP) with kinetic energy (escape depth correction) must be taken into account. Both theory and experiment indicate that the IMFP's are proportional to $\mathrm{KE}^{0.7}$. The net effect is that observed peak intensities differ from cross sections by a factor proportional to $\mathrm{KE}^{-0.8}$. ESCADT output therefore includes peak heights and areas that have been multiplied by $\mathrm{KE}^{0.4}$. These values are designated "AREAS*KINETIC ENERGY**0.3."

\section{PERfoRmance OF THE CODE}

Meaningful tests of ESCADT are complicated somewhat by the fact that changing instrument sensitivity and energy calibration may contribute to variations in repetitively determined peak areas or positions. One test of the code's ability to obtain peak positions and areas reproducibly involved processing five 4-min scans of the $\mathrm{Au} 4 \mathrm{f}$ doublet. The 
TABLE I

\section{SUCCESSIVE DETERMINATIONS OF THE Au if PEAK POSITIONS AND AREAS}

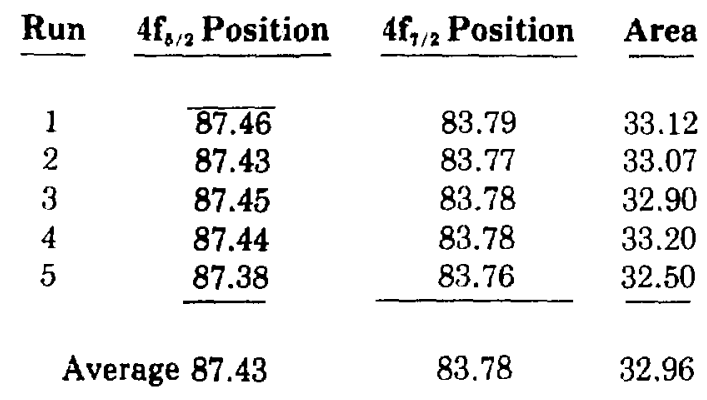

data were acquired after the instrument had been on for about $6 \mathrm{~h}$ and was thermally equilibrated. The peak areas and positions computed by ESCADT' are shown in Table $\mathbf{I}$.

The standard deviations in the positions of the $5 / 2$ and $7 / 2$ peaks are 0.031 and 0.011 , respectively. Moreover, the $5 / 2$ and $7 / 2$ peak positions are highly correlated $\left(r_{x y}=0.943\right)$ indicating that the peaks tend to shift in the same direction, presumably because of instrumental drift. The relative standard deviation for five determinations of the peak area was $0.85 \%$.

Although values for elemental photoionization cross sections are available in the literature ${ }^{a}$, they are not as well known as the intensity ratios of the spin-orbit doublets of individual elements. We have therefore chosen the latter to test the code. The ratio of the $\mathrm{Cu} 2 \mathrm{p}_{1 / 2}$ to $2 \mathrm{p}_{\mathrm{s} / 2}$ peak areas was found to be 0.5022 with a $95 \%$ confidence interval (CI) of 0.031 . The theoretical ratio is 0.5155 . A value of $0.849 \pm$ 0.037 (95\% CI) was obtained for the $\mathrm{Pb} 4 \mathrm{f}_{3 / 2}$ to $4 \mathrm{f}_{7 / 2}$ area ratio; this compares with a theoretical ratio of 0.783 . These results and others obtained with ESCADT indicate that precision and accuracy of 2$5 \%$ (RSD) should be routinely attainable. At present, the major limitation on accuracy is the unavailability of reliable standard intensities for many elements.

\section{REFERENCES}

1. K. Siegbahn, C. Nordling, A. Fahlman, R. Nordberg, K. Hamrin, J. Hedman, G, Johansson, T. Bergmark, S. E. Karlsson, I. Lindgren, and B. Lindberg, ESCA - Atomic, Molecular and Solid State Structure Studied by Means of Electron Spectroscopy (Almquist and Wiksells. Sweden, 1967).

2. C. D. Wagner, "Sensitivity of Detection of the Elements by Photoelectron Spectroscopy, Anal Chem. 44, 1050-1053 (1972).

3. T. E. Madey, C. D. Wagner and A. Joshi, "Surface Characterization of Catalysts Using Electron Spectroscopies: Results of a Round-Robin Sponsored by ASTM Committee D-32 on Catalysts," J. Electron Spectrosc. Relat. Phenom. 10, 359-388 (1977).

4. J. K. Sterrett, "Manual for Moving Polynomial Arc Smoothing," Aberdeen Proving Ground report No. 840 (November 1952).

5. A. Savitzky and M. J. E. Golay, "Smoothing and Differentiation of Data by Simplified Least Squares Procedures," Anal. Chem. 36, 1627-16:39 (1964).

6. D. W. Steinhaus, K. J. Fisher and R. Englemen, Jr., "Precision Computer Measurement of Spectra," Chem. Instrum. 3, 141 (1971).

7. J. M. Adams, S. Evans, P. I. Reid, J. M. Thomas, and M. J. Walters, "Quantitative Analysis of Aluminosilicates and Other Solids by X-ray Photoelectron Spectroscopy," Anal. Chem. 49. 2001-2008 (1977).

8. J. H. Scofield, "Hartree-Slater Subshell Photoionization Cross Sections at 1254 and 1487 eV," J. Electron Spectrosc. Relat. Phenom. 8, 129-137 (1976). 


\section{APPENDIX A}

\section{PROGRAM LISTING \\ LASL Identification No. LP1069}

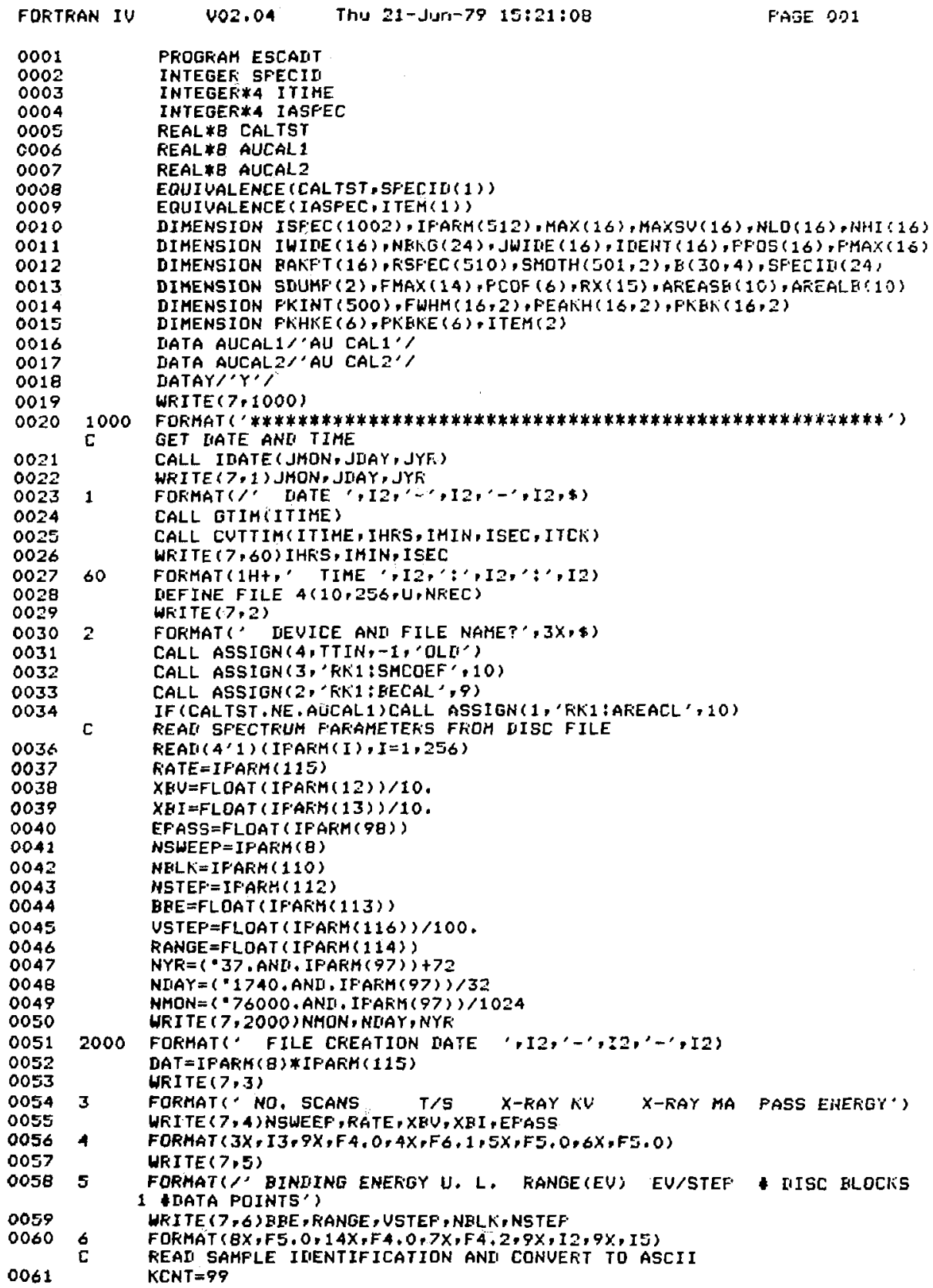




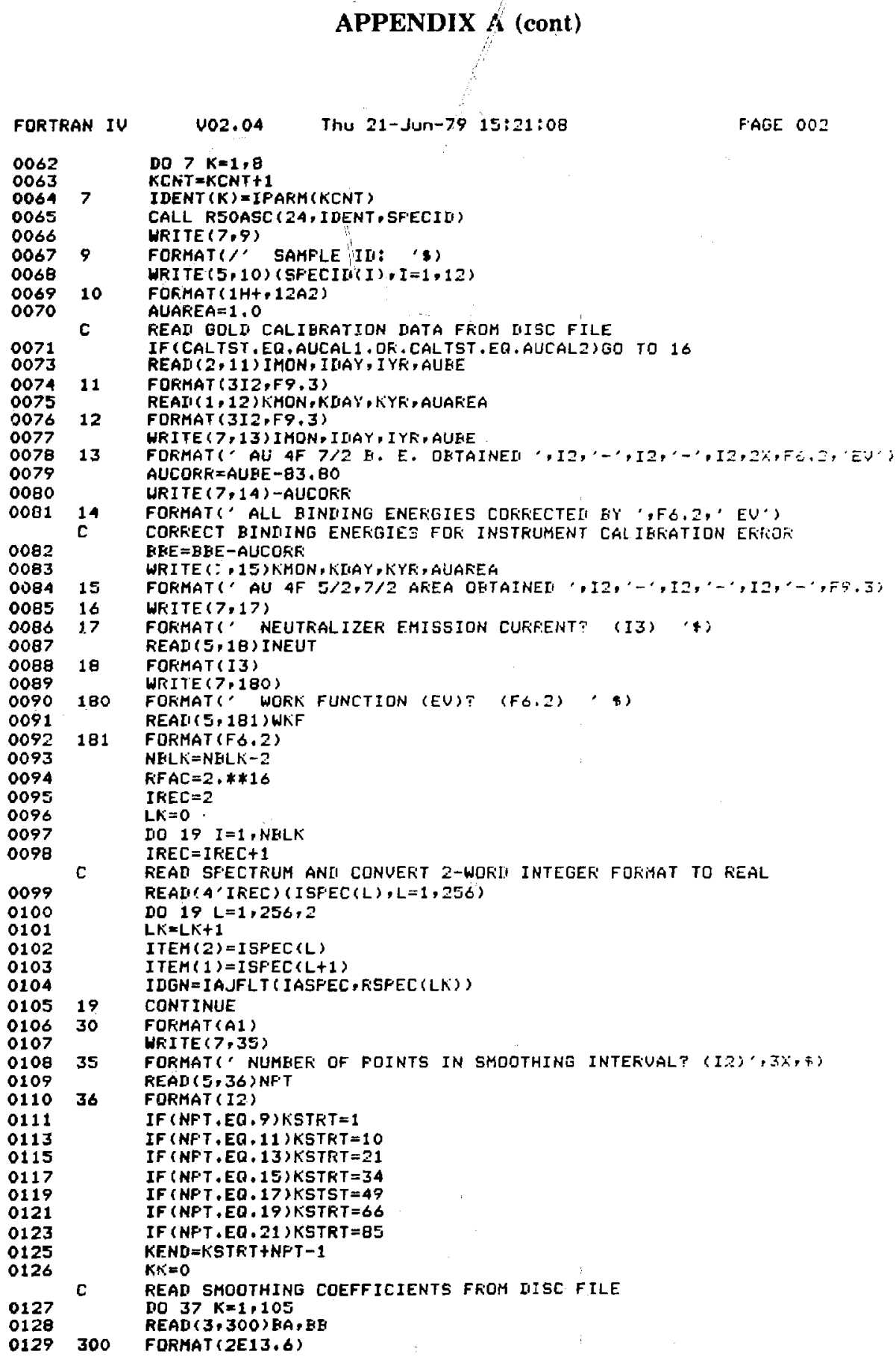

F.AGE 002 


\section{APPENDIX A (cont)}

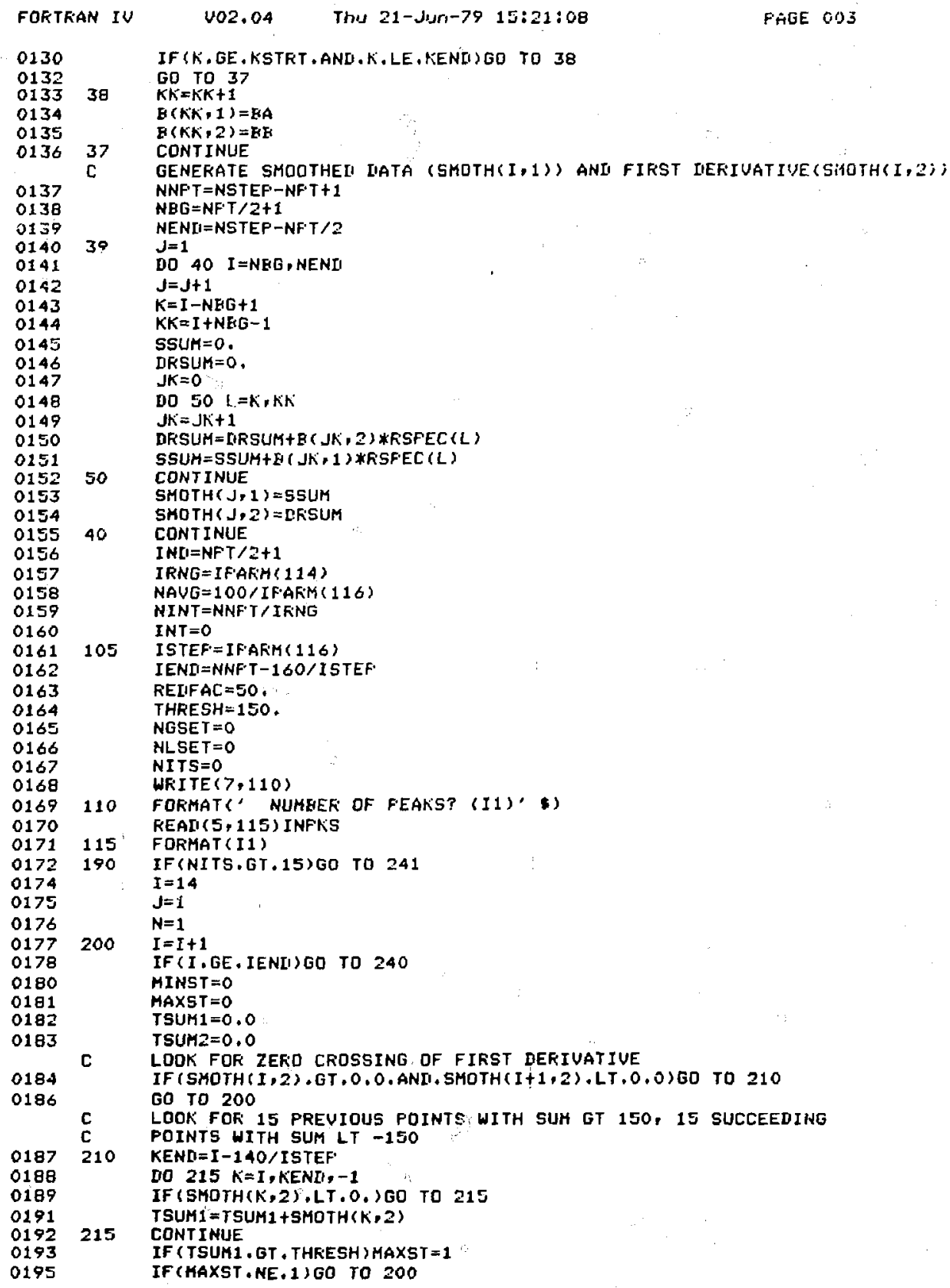




\section{APPENDIX A (cont)}

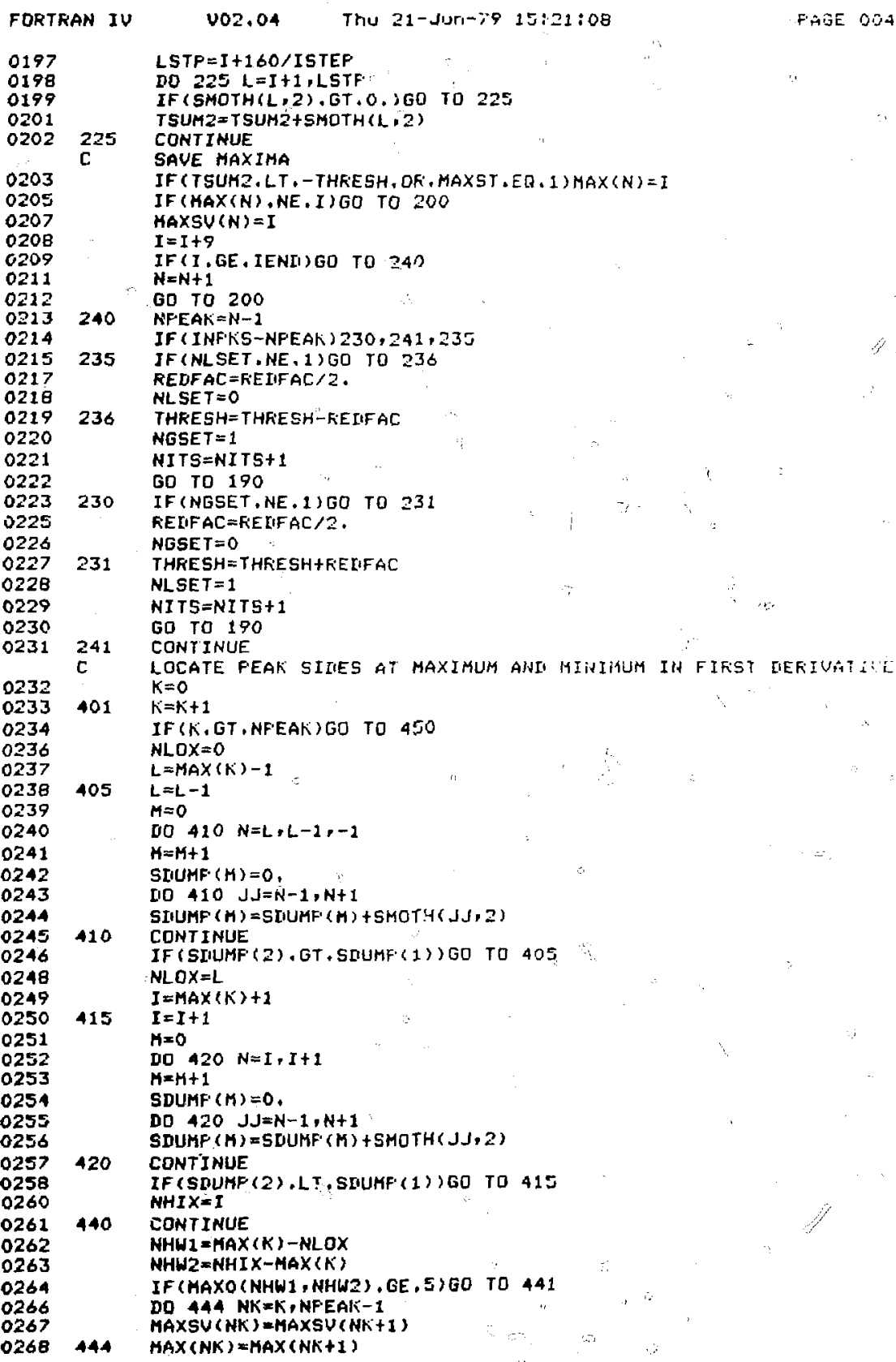




\section{APPFNIIX A (cont)}

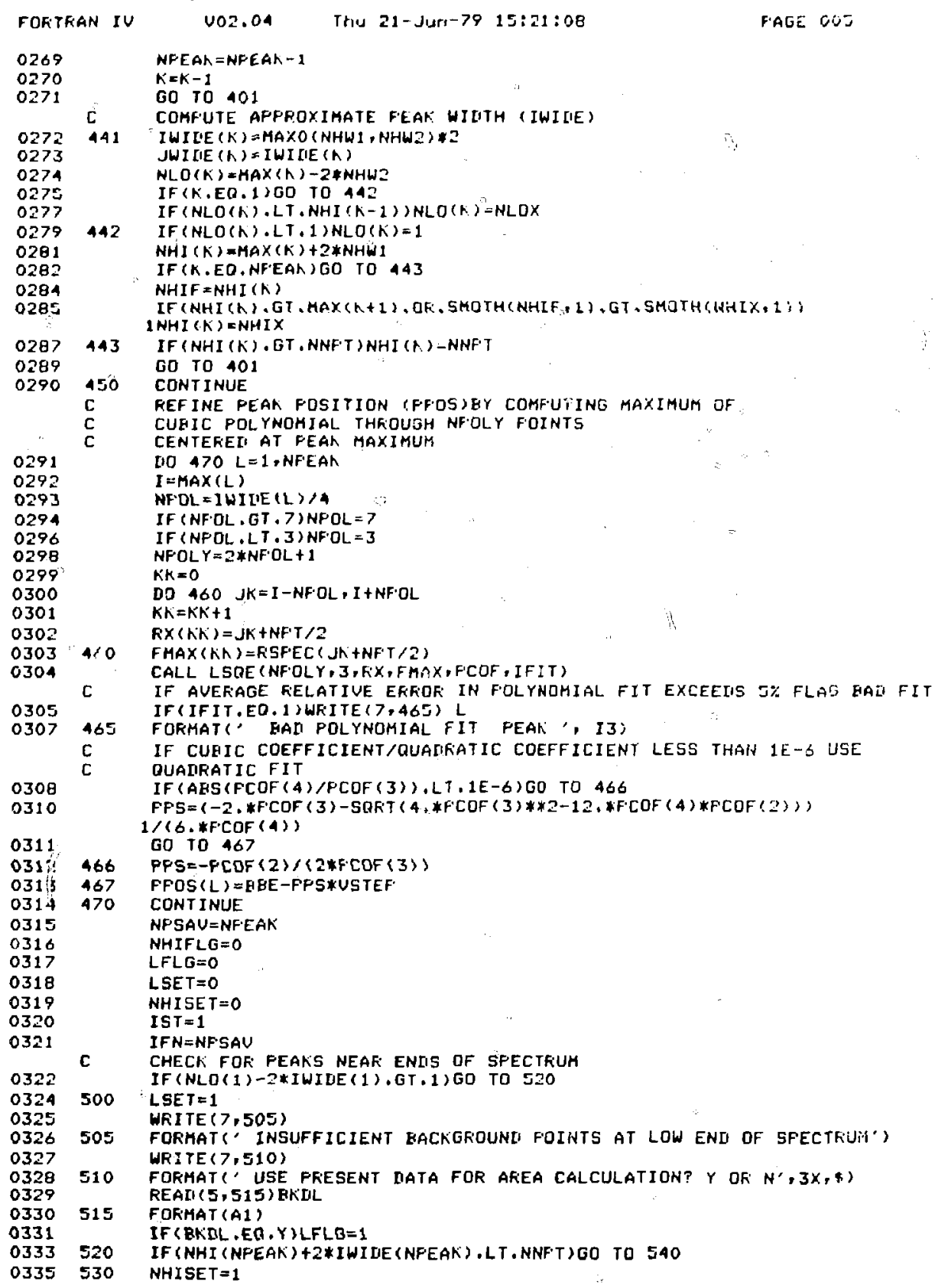




\section{APPENDIX A (cont)}

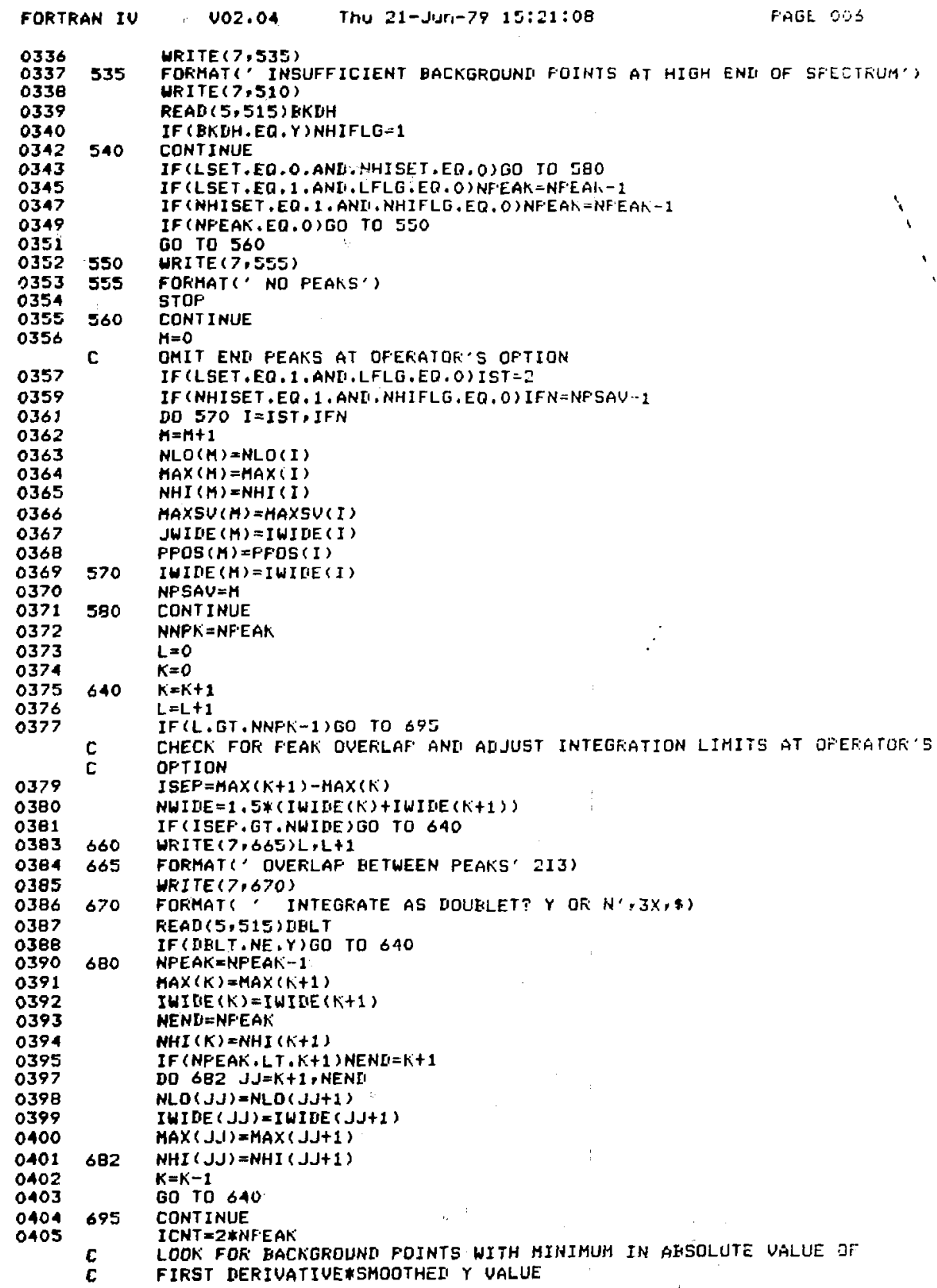




\section{APPENDIX A (cont)}

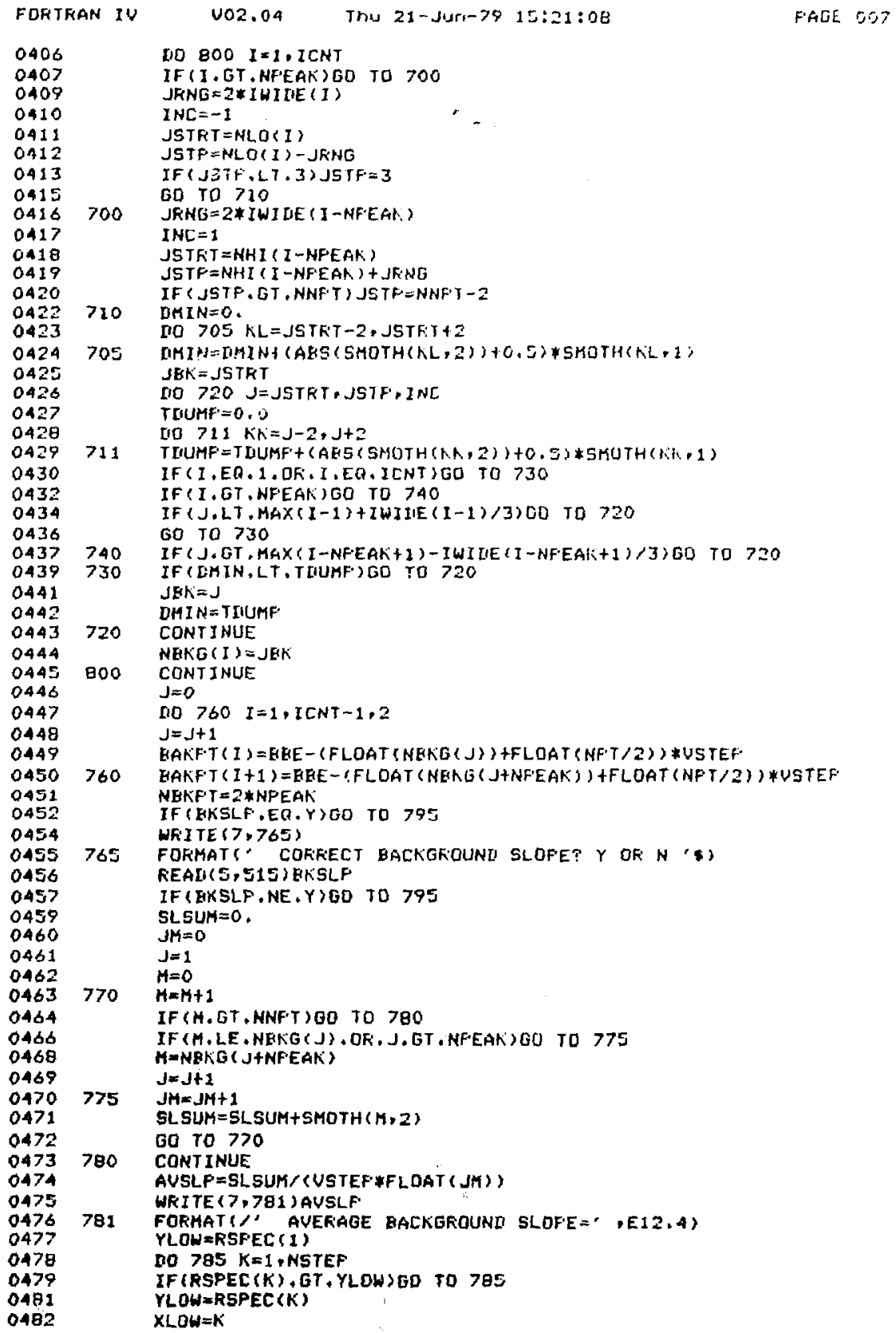




\section{APPENDIX A (cont)}

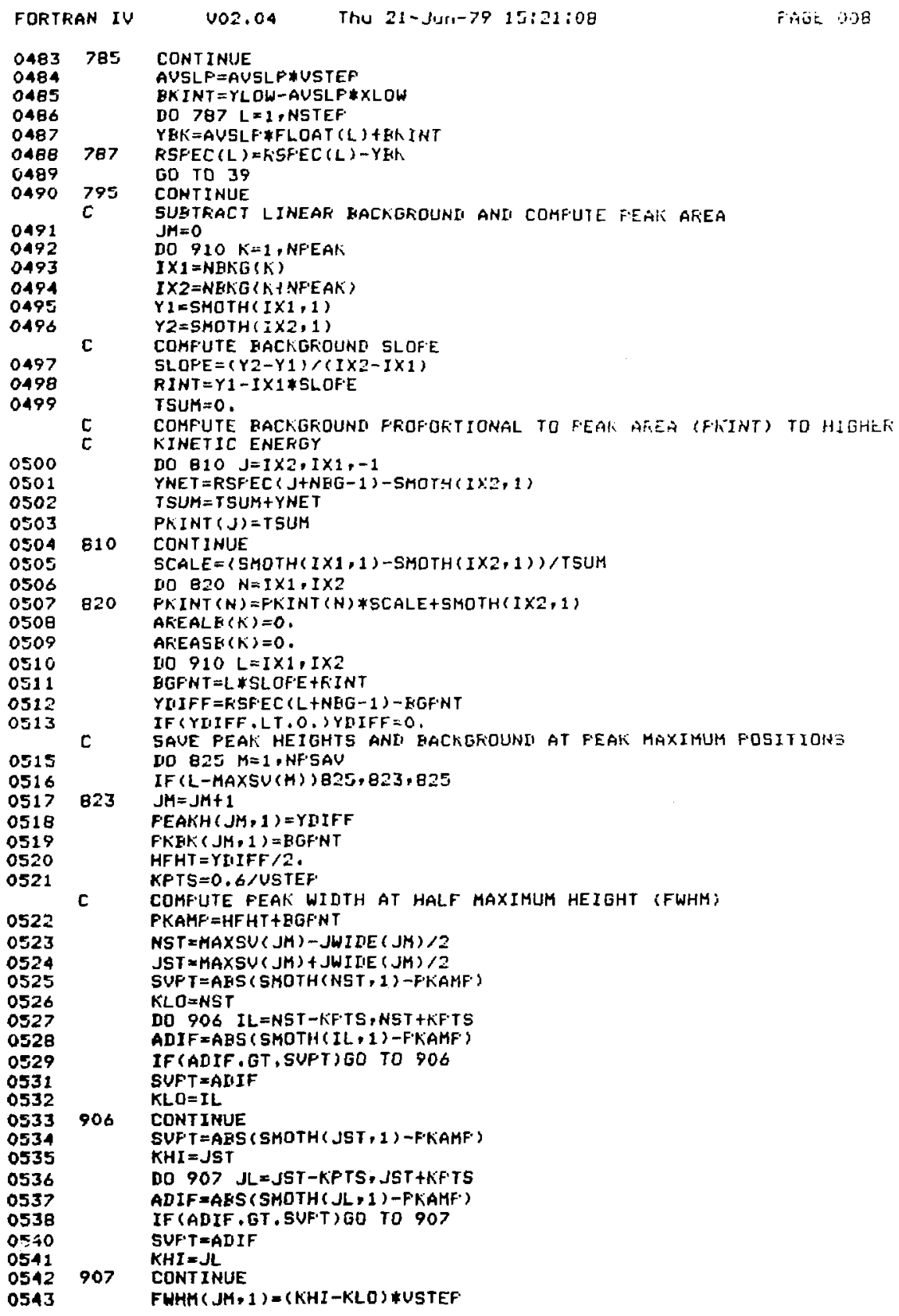




\section{APPENDIX A (cont)}

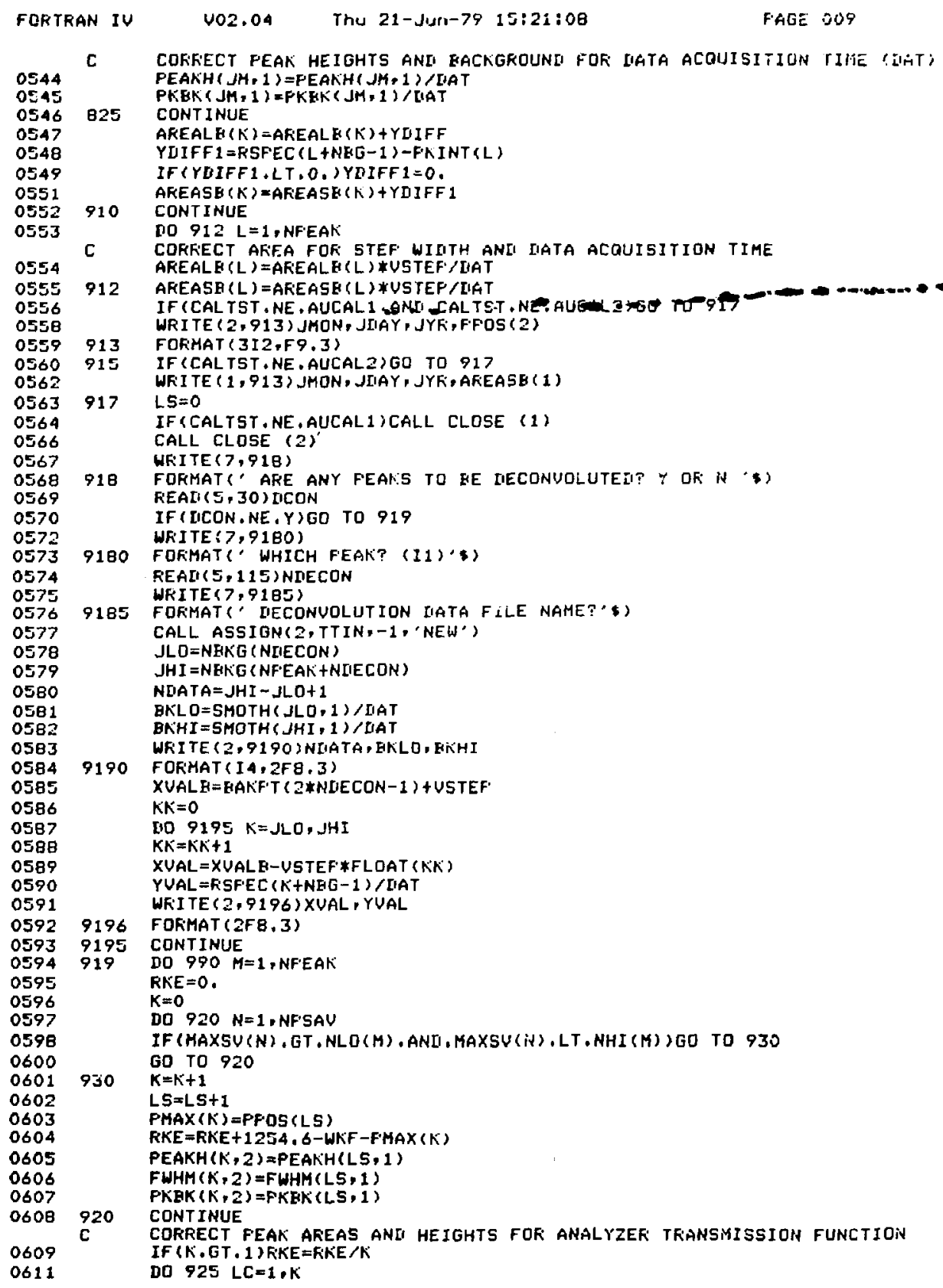




\section{APPENDIX A (cont)}

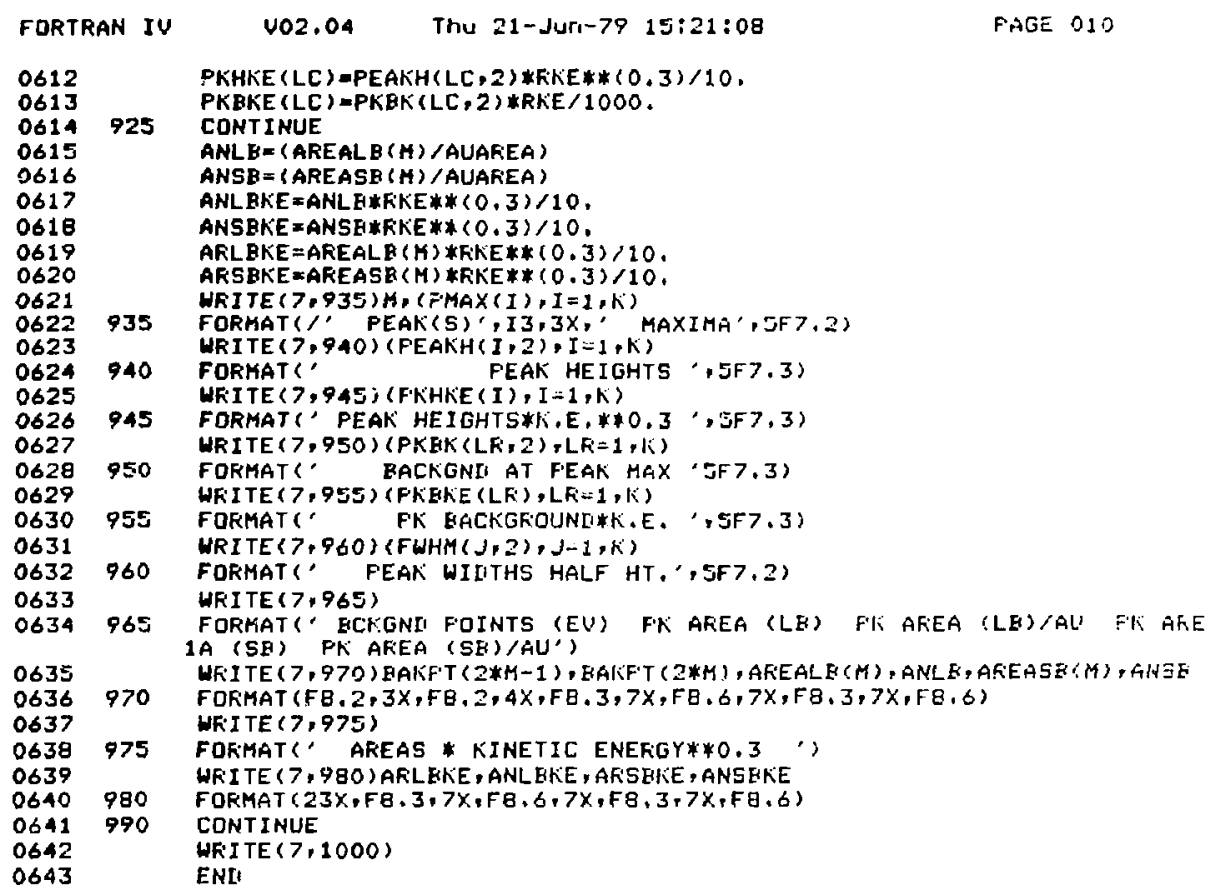




\section{APPENDIX A (cont)}

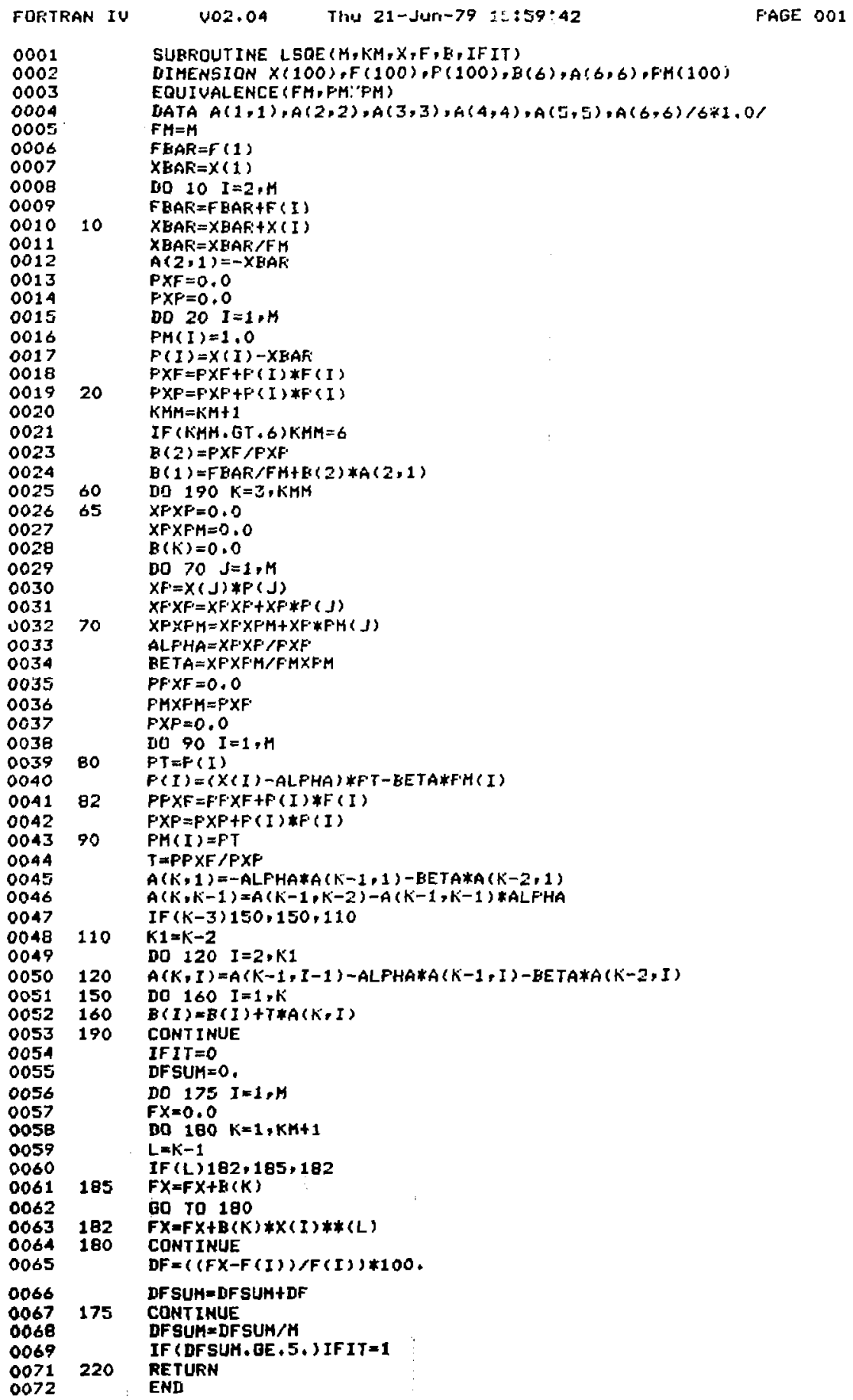

0001

0002

0003

0004

0005

0006

0007

0008

0009

0010

0011

0012

0013

0014

0015

0016

0017

0018

0019

0020

0021

0023

0024

0025

0026

0027

0028

0029

0030

0031

0032

0033

0034

0035

0036

0037

0038

0039

0040

0041

0042

0043

0044

0045

0046

0047

0048

0049

0050

0051

0052

0053

0054

0055

0056

0057

OOSB

0059

0060

0061

0062

0063

0064

0065

0066

0067

0068

0069

0071

0072

SLIRROUTINE LSOE ( $M, K M, X, F, E, I F I T)$

DIMENSION $X(100), F(100), F(100), B(6), A$, 6,6$), F H(100)$

EQUIVALENCE (FH, F'M:'PM)

DATA $A(1,1), A(2,2), A(3,3), A(4,4), A(5,5), A(6,6) / 6 * 1,0 /$

$F M=M$

FEAR $=F(1)$

$X \mathrm{BAR}=X(1)$

DO $10 I=2, H$

$F B A R=F B A R+F(I)$

$10 \quad X B A F=X B A F+X(I)$

$X B A F=X H A F / F M$

$A(2,1)=-X E A B$

$P X F=0.0$

$F X F=0,0$

DO $20 \quad I=1, M$

$P M(I)=1.0$

$P(I)=X(I)-X E A K$

$F X F=P X F+F(I)$ FF (I)

$20 \quad P X P=F \times F+F(I) * F^{\prime}(I)$

$K M M=K M+1$

IF $(K H M$. GT . 6) KKM $=6$

$\mathrm{E}(2)=\mathrm{P} \times \mathrm{F} / \mathrm{PXF}$

$B(1)=F H A R / F M+E(2) * A(2,1)$

$60 \mathrm{DD} 190 \mathrm{~K}=3, \mathrm{KMM}$

$X F \times F=0.0$

XFXFM=0.0

$B(K)=0.0$

Do $70 \mathrm{~J}=1, \mathrm{M}$

$X F=X(J) * F(J)$

$X F^{\prime} X F^{\prime}=X F^{\prime} X F^{\prime}+X F^{\prime} * F^{\prime}(J)$

$70 \quad X P X F M=X F \times X F M+X F * F M(1)$

ALFHA $=X F^{\prime} X F^{\prime} / F X F^{\circ}$

RETA $=X P X F \cdot M / F \cdot M X F \cdot M$

$P F X F=0.0$

FHXFH=PXF

$P X P=0.0$

I0 $90 \quad I=1, H$

BO $\quad P T=F(I)$

$F(I)=(X(I)-A L P H A) * F T-B E T A * F M(I)$

$82 \quad P F X F=F \cdot F \cdot P+F(I) * F(I)$

$P X P=F X P+F(I) * F(I)$

$P H(I)=P T$

$T=P P X F / P X P$

$A(K, 1)=-A L F H A * A(K-1,1)-B E T A * A(K-2,1)$

$A(K, k-1)=A(K-1, k-2)-A(k-1, k-1) * A L F \cdot H A$

IF $(K-3) 150,150,110$

$110 \quad K 1=K-2$

$\mathrm{DO} 120 \quad \mathrm{I}=2 \cdot \mathrm{K} 1$

$120 \quad A(K, I)=A(K-1, I-1)-A L F H A * A(K-1, I)-B E T A * A(K-2, I)$

150 DO $160 \quad I=1, K$

$160 \quad B(I)=B(I)+T * A(K r I)$

190 CONTINUE

IF $I T=0$

DFSUM $=0$.

DO $175 \quad I=1, M$

$F X=0.0$

DD $180 K=1, K M+1$

$L=K-1$

IF (L) $182,185,182$

$185 \quad F X=F X+B(K)$

$B 0$ TO 180

$182 \quad F X=F X+B(K) * X(I) * *(L)$

180 CONTINUE

$D F=((F X-F(I)) / F(I)) * 100$.

CONTIMUE

DF SUMXDFSUH/H

220

IF 'DFSUH, OE, 5, ) IF IT $=1$

RETURN

END 


\section{APPENDIX B}

DESCRIPTION OF ESCADT INPUT PARAMETERS

\section{Variable Name}

RATE

$\mathrm{XBV}$

XBI

EPASS

NSWEEP

NBLK

NSTEP

BBE

VSTEP

RANGE

INEUT

INPKS

RSPEC

$\mathrm{B}$

WKF

\section{Comments}

Data acquisition time at each point, in $\mathrm{ms}$. $\mathrm{X}$-ray source voltage in $\mathrm{kV}$, not used computationally.

$X$-ray source current in $\mathrm{mA}$, not used computationally.

Analyzer pass energy in $\mathrm{eV}$, not used computationally.

Number of scans.

Number of disk blocks occupied by the data file.

Number of spectral data points.

High binding energy limit of scan.

Digitization interval in $\mathrm{eV}$.

Scan range in $\mathrm{eV}$.

Flood gun emission current, not used computationally.

Number of peaks to be located (see text).

Array containing spectral ordinate values.

Array containing convoluting numbers for smoothing and differentiation (see text).

Spectrometer work function in $\mathrm{eV}$. 


\section{APPENDIX C}

TYPICAL PROGRAM RUN

(Operator responses are underlined.)

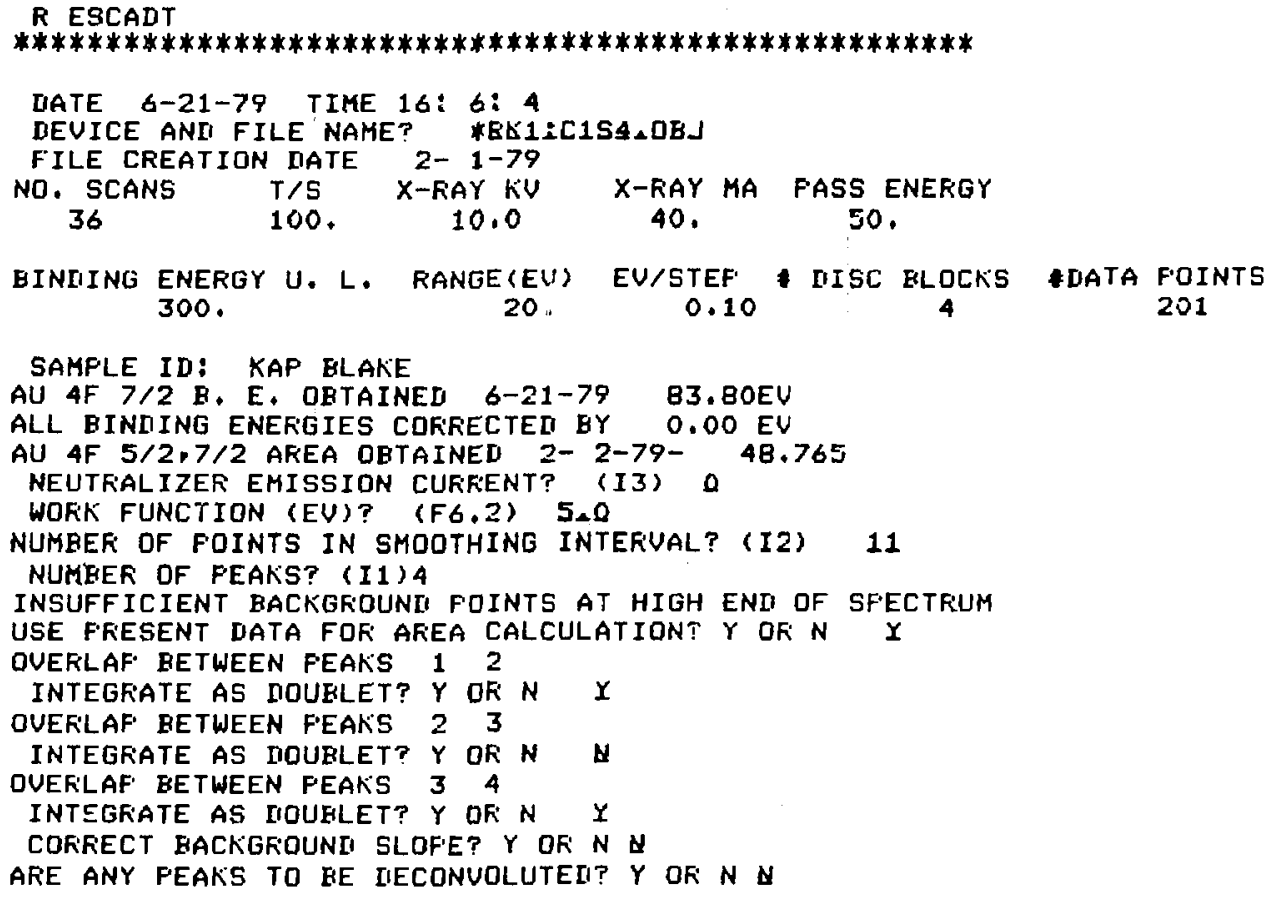




\section{APPENDIX D}

\section{QUADRATIC COEFFICIENTS FOR OBTAINING THE SMOOTHED VALUE AND SMOOTHED FIRST DERIVATIVE FOR POINT SPREADS OF NINE THROUGH TWENTY ONE}

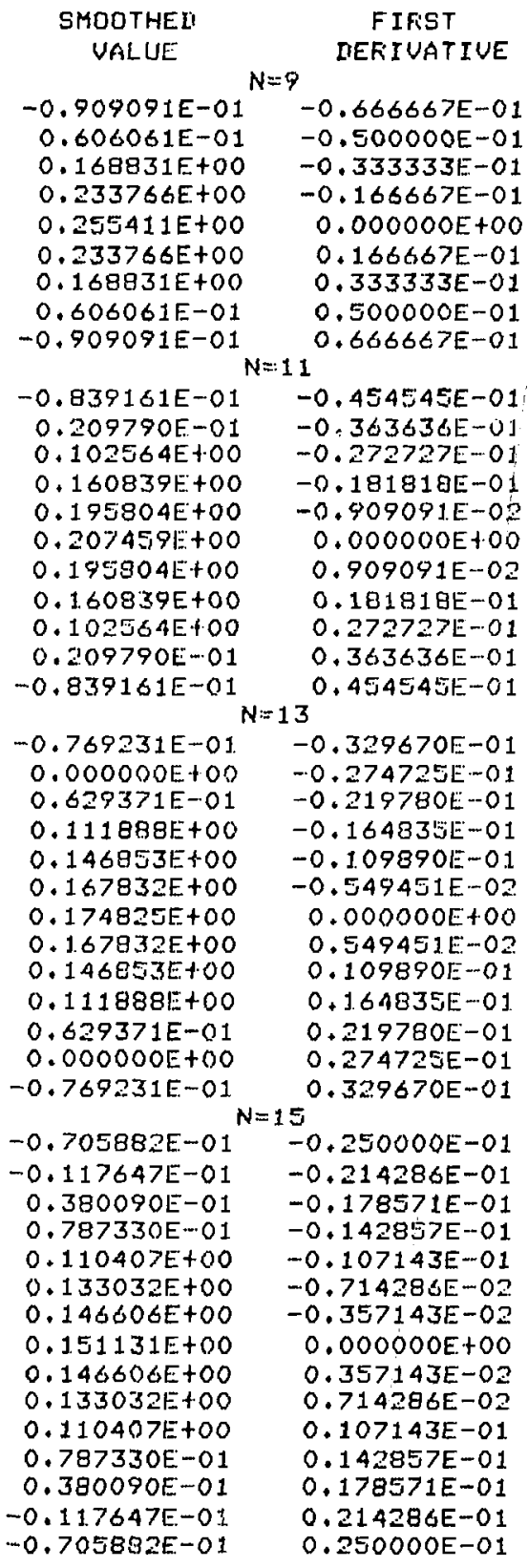

\begin{tabular}{|c|c|}
\hline $\begin{array}{l}\text { SMOOTHEI } \\
\text { VALUE }\end{array}$ & $\begin{array}{c}\text { FIF'ST } \\
\text { IIEFIIUATIVE }\end{array}$ \\
\hline \multicolumn{2}{|c|}{$N=17$} \\
\hline $\begin{array}{l}-0.650155 E-01 \\
-0.185758 E-01 \\
0.216718 E-01 \\
0.557275 E-01 \\
0.835913 E-01\end{array}$ & $\begin{array}{l}-0.196078 E-01 \\
-0.171569 E-01 \\
-0.147059 E-01 \\
-0.122549 E-01 \\
-0.980392 E-02\end{array}$ \\
\hline $0.105263 E+00$ & $-0.735254 E-02$ \\
\hline $\begin{array}{l}0.120743 E+00 \\
0.130031 E+00 \\
0.133127 E+00\end{array}$ & $\begin{array}{r}-0.49019 d E-02 \\
-0.245098 E-02 \\
0.000000 E+00\end{array}$ \\
\hline $\begin{array}{l}0.130031 E+00 \\
0.120743 E+00 \\
0.105263 E+00 \\
0.835913 E-01 \\
0.557275 E-01 \\
0.216713 E-01\end{array}$ & $\begin{array}{l}0.245098 E-02 \\
0.4901961 E-02 \\
0.735294 E-02 \\
0.990392 E-02 \\
0.122549 E-01 \\
0.147059 E-01\end{array}$ \\
\hline $\begin{array}{l}-0.185758 E-01 \\
-0.650155 E-01\end{array}$ & $\begin{array}{l}0.171569 E-01 \\
0.196078 E-01\end{array}$ \\
\hline \multicolumn{2}{|c|}{$N=1.9$} \\
\hline $\begin{array}{l}-0.601504 E-01 \\
-0.225564 E-01\end{array}$ & $\begin{array}{l}-0.157895 E-01 \\
-0.140351 E-01\end{array}$ \\
\hline $0.108148 E-01$ & $-0.122807 E-01$ \\
\hline $\begin{array}{l}0.393631 E-01 \\
0.636886 E-01\end{array}$ & $\begin{array}{l}-0.1 .05: \\
-0.8771\end{array}$ \\
\hline $\begin{array}{l}0.835913 E-01 \\
0.990712 E-01 \\
0.110128 E+00 \\
0.116762 E+00\end{array}$ & $\begin{array}{l}-0.701754 E-02 \\
-0.526316 E-02 \\
-0.350977 E-02 \\
-0.175439 E-02\end{array}$ \\
\hline $\begin{array}{l}0.118974 E+00 \\
0.116762 E+00 \\
0.110128 E+00 \\
0.990712 E-01 \\
0.835913 E-01 .\end{array}$ & $\begin{array}{l}0.000000 E+00 \\
0.175439 E-02 \\
0.350377 E-02 \\
0.526315 E-02 \\
0.701754 E-02\end{array}$ \\
\hline $\begin{array}{l}0.636886 E-01 \\
0.393631 E-01 \\
0.106148 E-01\end{array}$ & $\begin{array}{l}0.87719 Z \mathrm{E} \cdots 02 \\
0.105263 E-01 \\
0.122807 \mathrm{0}-01\end{array}$ \\
\hline $\begin{array}{l}-0.225564 E-01 \\
-0.601504 E-01\end{array}$ & $\begin{array}{l}0.140351 E-01 \\
0.157895 E-01\end{array}$ \\
\hline \multicolumn{2}{|c|}{$N=21$} \\
\hline$-0.559006 E-01$ & -0.129 \\
\hline $\begin{array}{l}0.294214 E-02 \\
0.274600 E-01 .\end{array}$ & $\begin{array}{l}-0.103856 E-01 \\
-0.909091 E-02\end{array}$ \\
\hline $\begin{array}{l}0.487087 E-01 \\
0.666835 E-01\end{array}$ & $\begin{array}{l}-0.7792 \\
-0.6493\end{array}$ \\
\hline $0.813992 \mathrm{E}-01$ & -0.5194 \\
\hline $\begin{array}{l}0.928408 E-01 \\
0.101013 E+00\end{array}$ & $\begin{array}{l}-0.3896 \\
-0.2597\end{array}$ \\
\hline 7E+OO & -0.1298 \\
\hline $\begin{array}{l}0.107551 E+00 \\
0.105917 E+00\end{array}$ & $\begin{array}{l}0.0000 \\
0.1298\end{array}$ \\
\hline $0+101013 E+00$ & $0.259740 E-02$ \\
\hline $\begin{array}{l}0.928 \\
0.813\end{array}$ & $\begin{array}{l}0.3896 \\
0.51 .94\end{array}$ \\
\hline $0+666885 E-01$ & $0.649351 . E-02$ \\
\hline $\begin{array}{l}0.487087 E-01 \\
0.274600 E-01\end{array}$ & $\begin{array}{l}0.779221 \mathrm{E}-02 \\
0.909091 \mathrm{E}-02\end{array}$ \\
\hline & \\
\hline 590061 & $\begin{array}{l}0.11 .6883 \mathrm{E}-01 \\
0.129870 \mathrm{E}-01\end{array}$ \\
\hline
\end{tabular}

